\title{
Comparison Study of Time-varying Seismic Fragility of Precast Segmental and Cast-in-place Bridge Columns in High-speed Railway Bridges
}

Yan Liang

Zhengzhou University

Qing-He Li

Zhengzhou University

Pan-Jie Li ( $\sim$ lipanjie@zzu.edu.cn )

Zhengzhou University

Jing-Xiao Shu

Zhengzhou University

Yang Cao

Zhengzhou University

\section{Research Article}

Keywords: seismic fragility, time-varying, precast segmental bridge column, damage state

Posted Date: January 18th, 2022

DOI: https://doi.org/10.21203/rs.3.rs-1259604/v1

License: (9) This work is licensed under a Creative Commons Attribution 4.0 International License.

Read Full License 


\title{
Comparison study of time-varying seismic fragility of precast segmental and cast-in-place bridge columns in high-speed railway bridges
}

\author{
Yan Liang1, Qing-He Li², Pan-Jie Li*3, Jing-Xiao Shu, Yang Cao ${ }^{5}$. \\ School of Civil Engineering, Zhengzhou Univ., 100 Kexuedadao Rd, Zhengzhou, 450001, China. \\ (*Corresponding Author: Pan-Jie Li, E-mail: lipanjie@zzu.edu.cn)
}

\begin{abstract}
Anxiety about the long-term seismic performance of precast segmental bridge columns (PSBCs) limits their wide application in harsh environments and high intensities. However, railway route selection inevitably occurs in offshore areas, and it is urgent to study the seismic performance of the PSBC considering environmental erosion and seismic effects. In order to To study the application of precast segmental bridge columns (PSBCs) in offshore high intensity areas, this paper comprehensively compares the time-varying seismic fragility of precast segmental and cast-in-place bridge columns (CPBCs) in high-speed railway bridges. Based on an offshore high-speed railway column, finite element models of representative PSBCs and CPBCs are established and verified by experiments. Then, the verified finite models are utilized to implement the time-varying fragility analysis by considering chloride ion erosion under four damage states. The main conclusions are as follows: the exceeding probabilities of PSBC and CPBC are close in intact bridges under different damage states and seismic intensities. With the prolongation of bridge service time, the exceeding probabilities of PSBC increase more rapidly than those of CPBC due to the discontinuity of PSBC segments, which leads to the acceleration of corrosion of steel bars. When the columns reach the design working life, the exceeding probability and PGA median of PSBC are higher than those of CPBC columns under four damage states. Taking the medium damage state as an example, the maximum exceeding probability of PSBC and CPBC was $97.2 \%$ and $89.1 \%$ at the medium damage state, and the PGA median of PSBC was $24 \%$ lower than that of CPBC at 100 years. This work provides a theoretical foundation for the better application of PSBC in offshore high intensity areas.
\end{abstract}

Keywords: seismic fragility, time-varying, precast segmental bridge column, damage state.

\section{Introduction}

In recent decades, researchers have shown an increased interest in modular construction of precast structures due to their lower environmental pollution, fast construction speed and reliable component quality. In the field of the bridge engineering, precast segmental construction has been widely used in superstructures and substructures(Kashani et al., 2019). However, the application of precast components in the substructure occurred later than that in the superstructure. PSBC was first applied to JFK Causeway in Texas in the 1970s, and the bridge community has realized the obvious advantages of prefabricated columns. Compared with PSBC, the use of precast bridge columns can improve the 
engineering quality, and reduce the number of on-site personnel and the environmental impact(Sideris et al., 2014; Zhang Y, 2019). However, the anxieties of the long-term seismic performance of PSBC limit its application in high -intensity and offshore environmental areas(Hung et al., 2017). Therefore, the time-varying seismic vulnerability of the CPBC should be studied and compared with that of the PSBC in detail.

Seismic vulnerability analysis is widely used for the seismic performance of investigated bridges and is a part of the seismic risk analysis framework of the Pacific Earthquake Engineering Research Center (PEER)(Rao et al., 2016). It quantifies the exceeding probability of structural or component damage in earthquakes. In the offshore environment, corrosion deterioration (especially caused by chloride ions) is considered to be the key factor affecting the quantification of bridge vulnerability. The probability of bridge damage increases with the extension of service time(Liang et al., 2020, 2021). Meanwhile, many coastal areas are high -intensity zones. The seismic performance of cast-in-place bridges is expected to be significantly lower than their design performance under the combined action of earthquakes and chloride ion corrosion(Ou \& Nguyen, 2016; Yuan et al., 2017). Numerous studies of the time-varying vulnerability of cast-in-place bridges have been reported considering the accelerated degradation of materials in coastal areas and earthquake impacts in fault zones. Biondini proposed a probabilistic approach to predict the lifetime seismic performance of concrete bridges exposed to aggressive environments (Biondini et al., 2014). Li established a framework for evaluating the time-varying seismic performance of uncertain degraded $\mathrm{CPBC}$ by considering material parameters, corrosion initiation time and uncertainty of ground motion ( $\mathrm{Li}$ et al., 2018). Cheng proposed a seismic vulnerability analysis method for CPBC corrosion degradation based on a time-varying estimation of the displacement ratio as the bearing capacity index(Cheng et al., 2019).Based on the Duracrete model and previous experimental results, Li determined the probability distribution types and statistical characteristics of various environmental and corrosion parameters, and a framework for analyzing the seismic vulnerability of CPBC subjected to chloride ion erosion was proposed (Li et al., 2020).

PSBC has a different structural composition than $\mathrm{CPBC}$, which includes joints, energy dissipation (ED) bars and unbonded prestressed tendon (PT) strands(Li et al., 2017). Its working performance is very different from CPBC. Due to the discontinuity between segments, the seismic performance of PSBC is recognized to be weaker than that of CPBC(Jia et al., 2020). Scholars at home and abroad have performed many studies on the working performance of PSBCs, such as cyclic load tests(Li et al., 2017), shaking table tests(Li et al., 2019), and impact tests(Do et al., 2019) and so on. The PSBC is more likely to show quasi -elastic behavior in medium and small earthquakes(Tong et al., 2021). Through the experimental study (Zhanghua et al., 2021), an appropriate slenderness ratio and longitudinal bars can significantly improve the deformation capacity of PSBC under earthquakes. These studies enable PSBC to be widely used in low intensity areas. Some scholars have studied the seismic vulnerability of PSBCs in high -intensity areas. Lee and Billington 
analyzed the seismic vulnerability of a bridge system supported by PSBC in the PBEE framework and evaluated its economic loss(Lee \& Billington, 2011). Ehsan Ahmadi used incremental dynamic analysis (IDA) to generate a vulnerability curve for studying the vulnerability of PSBC, and the results indicated that low columns are more prone to earthquake collapse than slender columns(Ahmadi \& Kashani, 2021). However, many high-intensity areas are in coastal areas, and when bridges are built in these areas, the structures are vulnerable to chloride ion corrosion in seawater. Therefore, the coupling effect of material performance degradation and earthquakes should be considered. Scholars at home and abroad rarely study the time-varying seismic vulnerability of PSBCs. From the above review, this paper studies the time-varying seismic vulnerability of PSBC on the basis of predecessors and compares it with that of CPBC.

This paper makes a comparative study on the long-term seismic vulnerability of PSBCs and CPBCs. First, the bridge model is established according to an example bridge in an offshore high-intensity area in Section 2, and then the established model is tested and verified to verify the effectiveness of the modeling method in Section 3. In Section 4, the displacement ductility ratio is selected as the time-varying seismic fragility index, the ground motion meeting the local site conditions is selected from PEER for probabilistic seismic demand analysis, the fragility curve is drawn, and the median PGA is obtained. The main conclusions are drawn in Section 5.

\section{Establishment of Finite Element Model}

\subsection{Description of the finite element model of PSBC and CPBC}

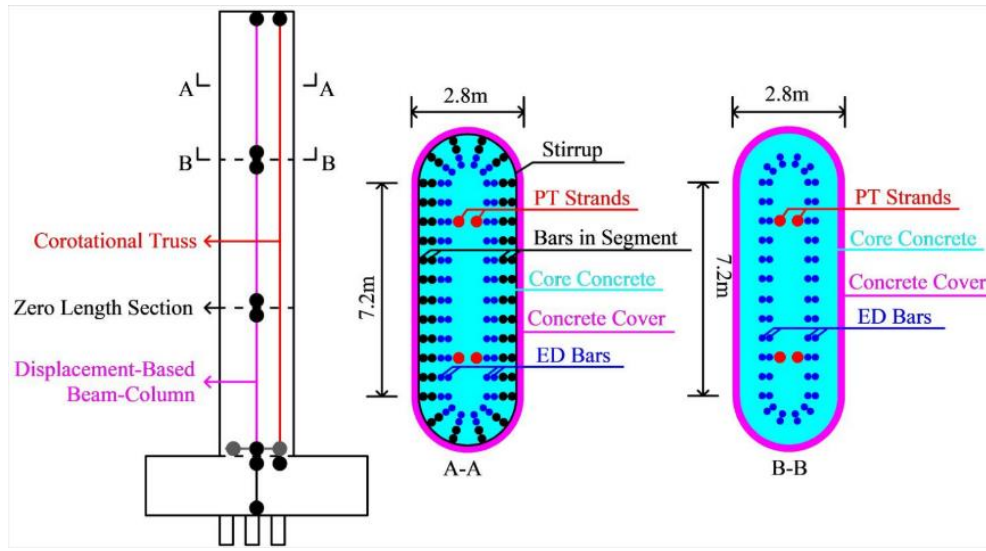

(a)PSBC model

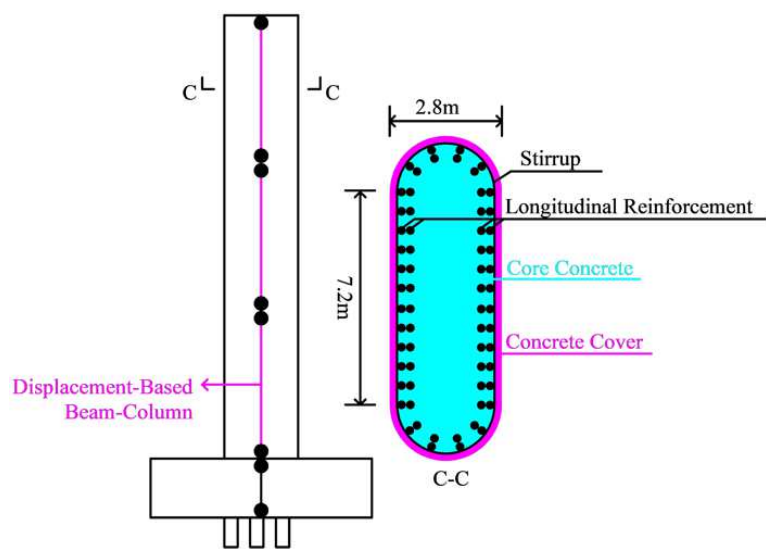

(b) CPBC model

Fig.1 Finite element model of PSBC and CPBC

Without loss of generality, a typical five-span continuous rigid frame high-speed railway bridge is adopted in the present study as the reference model. The site conditions are class 2, the seismic fortification intensity is 8 degrees, and the designed service life is 100 years. The concrete grade is $\mathrm{C} 45$, and the protective layer thickness is $45 \mathrm{~mm}$. The stirrups in PSBC and CPBC are 10mm HPB300, and the longitudinal bars are 32mm HRB500, with reinforcement ratios of $0.56 \%$ 
and $0.70 \%$, respectively. In CPBC, 28mm HRB500 steel bar is used for ED bars and 1860 steel strand with a diameter of $15.2 \mathrm{~mm}$ is used for unbonded PT strands, ED bars and unbonded PT strands run through all sections.

Taking the column of the high-speed railway bridge as an example, the finite element model of PSBC and CPBC is established as shown in Fig.1. The models are simulated using fiber-based nonlinear elements in OpenSees which can effectively simulate the hysterical behavior of columns and dynamic response under earthquake excitation(Pan et al., 2017). Each segment of PSBC and the body of CPBC are all simulated by Displacement-Based Beam-Column element, the bottom node is consolidated, and the top node is released. Different from CPBC, in the joint section of PSBC, the ED bar fiber is decorated. The joint sections between the column segments are simulated by ZeroLengthSection element in OpenSees. The existing PSBC test results showed that the joints will open and close under the action of horizontal displacement, and there is basically no shear dislocation between the segments (Chou \& Chen, 2006; Ou et al., 2007, 2010, 2010) . Corotational Truss element is used to simulate unbonded PT strands, the division of Corotational Truss element corresponds to Displacement-based Beam-Column element of the column body.

\subsection{Time-varying material and mechanical properties}

Concrete 02 is selected to model the constitutive behavior of the concrete, which can better estimate the residual deformation of the concrete(Kent \& Park, 1990). The reinforcing bars is modelled using the steel02 in OpenSees, which is capable of considering isotropic strain hardening and the Bauschinger effect(Spacone \& Filippou, 1991). The parameter values in the steel model for longitudinal bars are: $f_{y}=500 \mathrm{MPa}, f_{u}=630 \mathrm{MPa}, E_{s}=1.93 \times 10^{5} \mathrm{MPa}, E_{s h}=6.0 \times 10^{3} \mathrm{MPa}$, $\varepsilon_{s h}=0.01, \varepsilon_{s u}=0.15$, the corresponding values for stirrups are $f_{y}=300 \mathrm{MPa}, f_{u}=420 \mathrm{MPa}, E_{s}=1.93 \times 10^{5} \mathrm{MPa}, E_{s h}=6.0 \times 10^{3} \mathrm{MPa}$, $\varepsilon_{s h}=0.01, \varepsilon_{s u}=0.15$.

In offshore environments, bridge columns are susceptible to chloride ion corrosion in seawater. The diffusion mechanism of chloride ions in RC structures with different exposure conditions is different. The initial corrosion time of reinforcement considering chloride ion corrosion is:

$$
t_{i}=\frac{c^{2}}{4 D_{c}}\left[\operatorname{erf}^{-1}\left(1-\frac{M_{\mathrm{cr}}}{M_{\mathrm{S}}}\right)\right]^{-2} \times 10^{-6}+0.2 t_{1}
$$

where $t_{i}$ is the beginning corrosion time of the reinforcement (year); $c$ is the thickness of the concrete cover (mm); $D_{c}$ is the diffusivity coefficient of chloride ions ( $\mathrm{mm}^{2} / \mathrm{year}$ ); $\operatorname{erf}($.$) represents the Gauss error function; M_{c r}$ is the critical chloride concentration of reinforcement corrosion $\left(\mathrm{kg} / \mathrm{m}^{3}\right) ; M_{s}$ is the chloride concentration at the concrete surface $\left(\mathrm{kg} / \mathrm{m}^{3}\right) ; t_{i}$ is the accumulation time for chloride ions to reach a stable value on the concrete surface.

The rust expansion cracking time of the concrete protective layer includes the initial corrosion time of the reinforcement and the migration and diffusion time process of the corrosion products. It can be expressed as follows(Liang 
et al., 2019):

$$
t_{\mathrm{cr}}=t_{\mathrm{i}}+t_{\mathrm{c}}
$$

where $t_{c r}$ is the rust expansion cracking time of the concrete cover, $t_{c}$ is the time from steel bar corrosion to concrete cracking.

After the concrete cover cracks, the corrosion rate of reinforcement further accelerates with the deepening of chloride ion erosion, the concrete cover cracks and the corrosion rate of reinforcement accelerates, the time-variant diameter model of corroded reinforcement considering the cracking of concrete cover is as follows(Stewart \& Rosowsky, 1998):

$$
d(t)= \begin{cases}d_{0} & t \leq t_{\mathrm{i}} \\ d_{0}-2 \lambda_{1}\left(t-t_{\mathrm{i}}\right) & t_{\mathrm{i}}<t \leq t_{\mathrm{cr}} \\ d_{0}-2 \lambda_{1}\left(t_{\mathrm{cr}}-t_{\mathrm{i}}\right)-2 \lambda_{2}\left(t-t_{\mathrm{cr}}\right) & t>t_{\mathrm{cr}}\end{cases}
$$

where, $d(t)$ is the time-variant diameter; $\mathrm{d}_{0}$ is the initial diameter of the reinforcement $(\mathrm{mm}) ; \lambda_{1}$ is the corrosion rate before the cracking of the concrete cover ( $\mathrm{mm} /$ year); $\lambda_{2}$ is the corrosion rate after the cracking of the concrete cover (mm/year).

The yield strength and ultimate strength of the reinforcement degenerated with the corrosion, and the degradation formula can be expressed as (Du et al., 2005).

$$
\begin{aligned}
& f_{\mathrm{y}, \text { corr }}=\left(1-\beta_{\mathrm{y}} Q_{\text {corr }}\right) f_{\mathrm{y}} \\
& f_{\mathrm{u}, \text { corr }}=\left(1-\beta_{\mathrm{u}} Q_{\text {corr }}\right) f_{\mathrm{u}} \\
& Q_{\text {corr }}=\left(\frac{D(t)}{d_{0}}\right)^{2}
\end{aligned}
$$

where $f_{y, c o r r}$ and $f_{u, c o r r}$ are the yield strength (MPa) and the ultimate strength (MPa) of the corroded reinforcement; $\beta y$ and $\beta_{u}$ are the reduction coefficients of the yield strength and the ultimate strength, which are taken as 0.0049 and 0.0065 respectively considering the field site of the investigated bridge; $f_{y}$ and $f_{u}$ are the yield strength (MPa) and ultimate strength $(\mathrm{MPa})$ of the reinforcement before corrosion; $Q_{\text {corr }}$ is the corrosion rate of the reinforcement.

Due to the deep location of the column PT strands in the engineering example, the equivalent concrete protective layer thickness is $181.72 \mathrm{~mm}$, and the corrosion time of the unbonded PT strands is 207.66 years, so the chloride ion corrosion effect of PT strands can be ignored.

Table1 Parameters related to reinforcement corrosion

\begin{tabular}{cccccc}
\hline \multirow{2}{*}{ Parameter } & Stirrup & $\begin{array}{c}\text { The first row of } \\
\text { reinforcement }\end{array}$ & $\begin{array}{c}\text { The second row of } \\
\text { reinforcement }\end{array}$ & $\begin{array}{c}\text { The first row } \\
\text { ED bars }\end{array}$ & $\begin{array}{c}\text { The second row } \\
\text { ED bars }\end{array}$ \\
\cline { 2 - 6 }
\end{tabular}




\begin{tabular}{|c|c|c|c|c|c|c|c|c|c|c|}
\hline & $\mathrm{CPBC}$ & PSBC & CPBC & PSBC & CPBC & PSBC & CPBC & PSBC & CPBC & PSBC \\
\hline$c(\mathrm{~mm})$ & 45 & 45 & 55 & 55 & 87 & 67 & - & 26.79 & - & 40.77 \\
\hline$D_{\mathrm{c}}\left(\mathrm{mm}^{2} /\right.$ year $)$ & 224.06 & 224.06 & 224.6 & 224.06 & 224.06 & 224.06 & - & 224.06 & - & 224.06 \\
\hline$M_{c r}\left(\mathrm{~kg} / \mathrm{m}^{3}\right)$ & 2.1 & 2.1 & 2.1 & 2.1 & 2.1 & 2.1 & - & 2.1 & - & 2.1 \\
\hline$M_{s}\left(\mathrm{~kg} / \mathrm{m}^{3}\right)$ & 3.618 & 3.618 & 3.618 & 3.618 & 3.618 & 3.618 & - & 3.618 & - & 3.618 \\
\hline$t_{i}($ year $)$ & 15.74 & 15.74 & 21.93 & 21.93 & 50.07 & 30.99 & - & 8.37 & - & 14.22 \\
\hline$t_{c r}$ (year) & 24.13 & 24.13 & 30.33 & 30.33 & 58.46 & 39.39 & - & 16.76 & - & 22.61 \\
\hline$\lambda_{1}(\mathrm{~mm} /$ year $)$ & 0.0121 & 0.0121 & 0.0099 & 0.0099 & 0.0063 & 0.0082 & - & 0.0204 & - & 0.0134 \\
\hline$\lambda_{2}(\mathrm{~mm} /$ year $)$ & 0.0304 & 0.0304 & 0.0248 & 0.0248 & 0.0157 & 0.0204 & - & 0.0509 & - & 0.0335 \\
\hline
\end{tabular}

The relevant parameters of reinforcement corrosion under chloride ion corrosion are shown in Table 1, according to the site conditions of the investigated bridge. Table 1 indicates that the initial corrosion time of bars in segment in Row 1 of CPBC and PSBC is later than that of stirrup and earlier than that of bars in segment in Row 2, the corrosion rate is slower than that of stirrup and faster than that of bars in segment in Row 2. The thickness of the concrete cover after equivalent cement mortar between PSBC joints is much less than that of the segment. The corrosion time of reinforcement in PSBC is earlier and faster than that in CPBC, and the corrosion of bars in the segment and ED bars in the through joint shall be considered. The joints of PSBC commonly adapt epoxy adhesive joints whose durability factor is identical to that of direct wet joints, so the chloride ion erosion effect at the joints should be considered in the form of direct wet joints in this paper. The farther the steel bar is from the concrete surface, the later the corrosion time, and the smaller the corrosion rate before and after cracking.

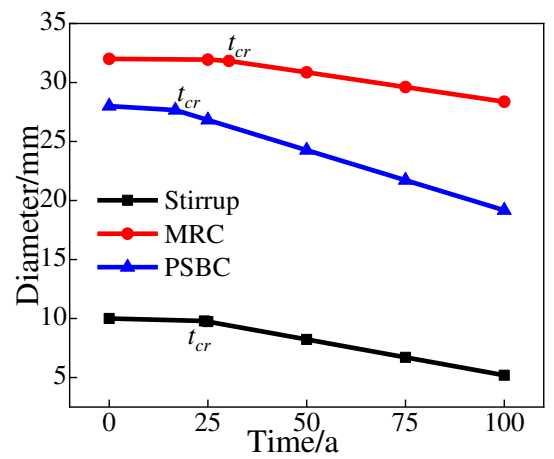

(a) Diameter

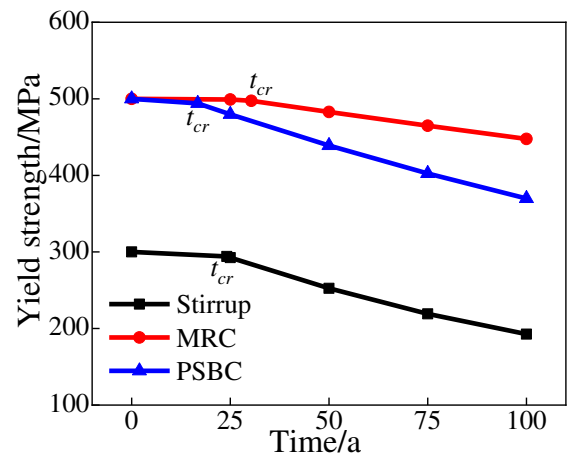

(b) Yield strength

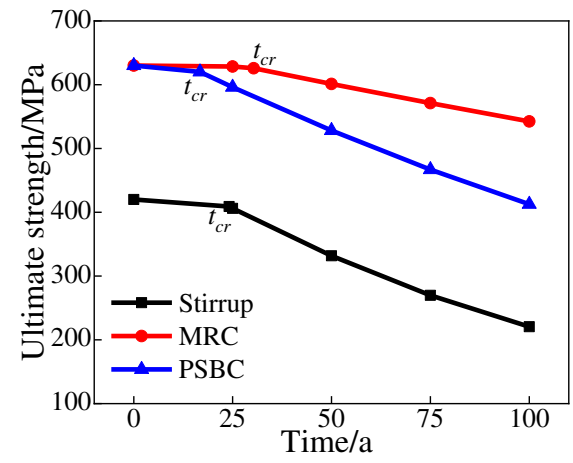

(c) Ultimate strength

Fig.2 Analysis of time-varying steel character

In the whole life cycle, the diameter, yield strength and ultimate strength of the reinforcement decrease with the service time extension. The stirrup is the outermost reinforcement, and the stirrup damage is stronger than that of the longitudinal bars and ED bars. Due to the same concrete cover of PSBC and CPBC, the stirrup damage degrees of PSBC and $\mathrm{CPBC}$ are the same. Compared with the second row of longitudinal bars of $\mathrm{CPBC}$, the first row of longitudinal bars of CPBC is easily eroded by chloride ions in seawater, and the mechanical performance of the material decreases the most. 
PSBC has joints, and the ED bars pass through the joints The ED bars in PSBC contact sea water first and are corroded by chloride ions in sea water, especially the first row of ED bars. The mechanical properties of the material decline the fastest, as shown in Fig. 2. After 100 years of service, the reinforcement diameter, yield strength and ultimate strength of CPBC are reduced by $11 \%, 10 \%$, and $14 \%$, respectively; the reinforcement diameter, yield strength and ultimate strength of PSBC are reduced by $32 \%, 26 \%$, and $35 \%$, respectively. The necessity of considering chloride ion corrosion is verified.

\section{The Verification of Finite Element Model}

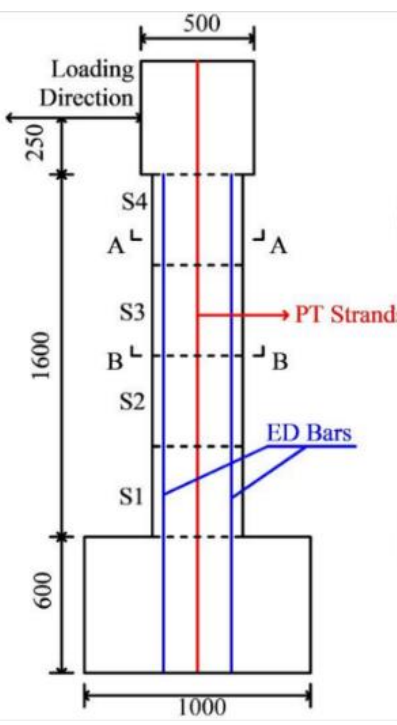

(a) Reference ${ }^{[33]}$ specimens

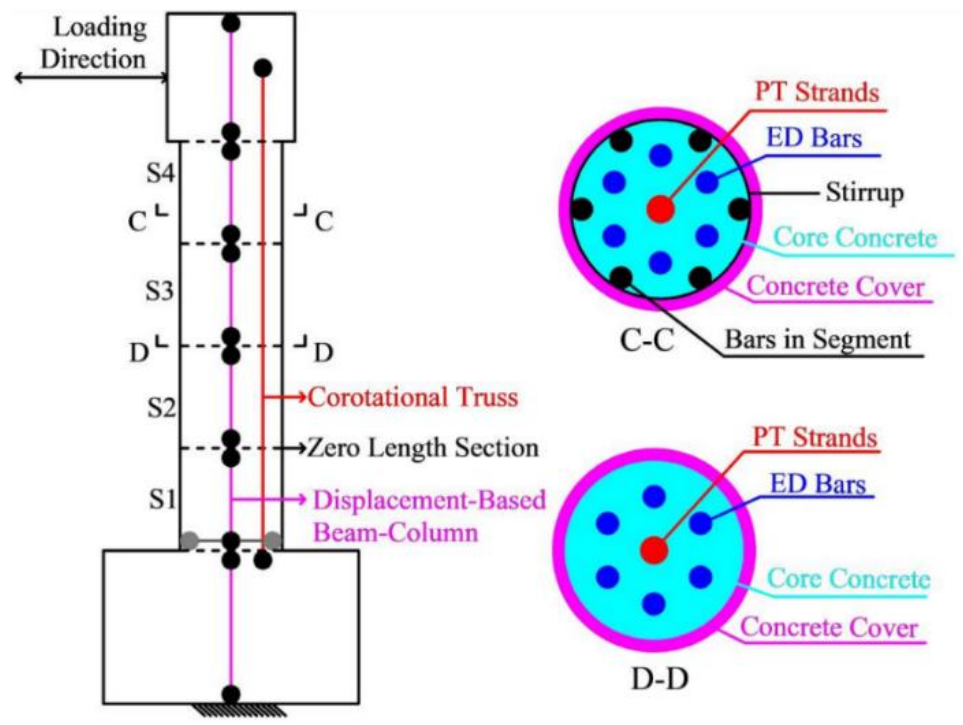

(b) Finite element model

Fig.3 The verification of PSBC model

The previous experimental results are used to verify the accuracy of the current modeling method in Section 2. Bu (Bu et al., 2015) compared and analyzed four reduced scale PSBC specimens with different reinforcement types and one CPBC specimen through experience tests. This paper selects the experimental results of the PSBC specimen for model verification. The experiment PSBC selected is shown in Fig.3 (a). The piles, column body and beam are cast with C40 concrete. The perforated unbonded PT strand ratio was $0.31 \%$, the initial tension was $252 \mathrm{kN}$, and the ED bar ratio was $0.71 \%$. The stirrup spacing of the $\mathrm{S} 1$ segment is $50 \mathrm{~mm}$, the stirrup ratio is $0.96 \%$, and the stirrup spacing and ratio of the others are $80 \mathrm{~mm}$ and $0.6 \%$, respectively. The FE model of the selected column was established by using the identical modeling method, and the corresponding model is shown in Fig. 3(b). In the experiment, the displacement-controlled method was used for the loading test process, and the controlled draft levels included $0.1 \%, 0.2 \%, 0.3 \%, 0.5 \%, 0.75 \%, 1 \%$, $1.5 \%, 2.0 \%, 2.5 \%, 3.0 \%, 3.5 \%, 4.0 \%, 4.5 \%, 5.0 \%, 6.0 \%$ and $7.0 \%$ with two cycles for each drift level. 


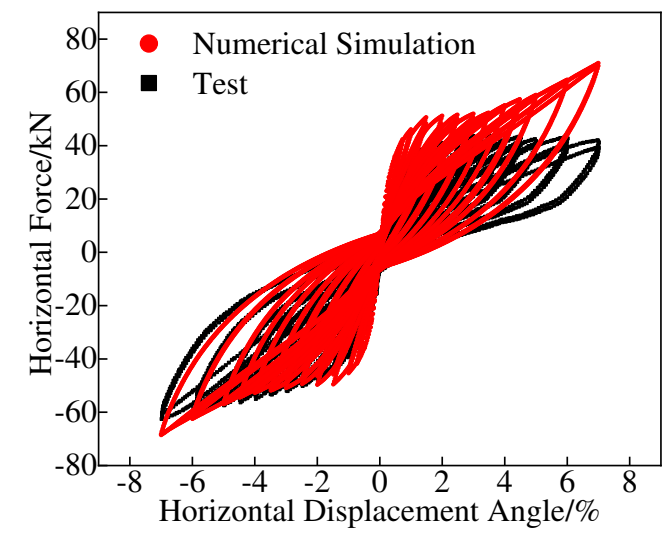

(a) Load displacement hysteretic curve

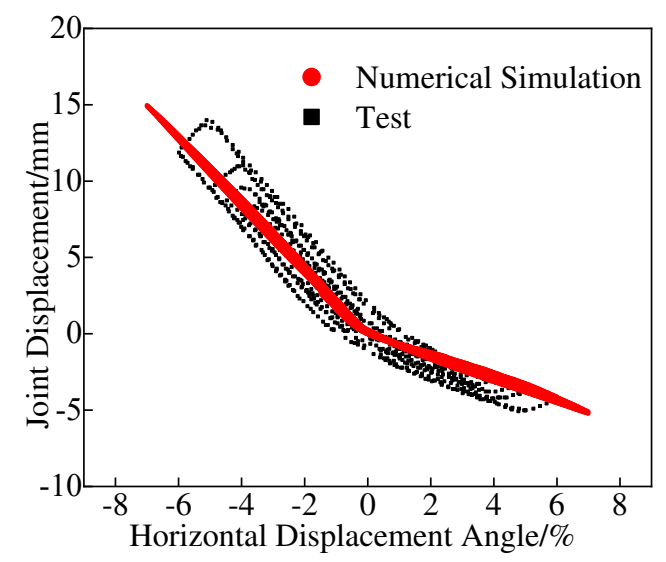

(c) Relative deformation of column bottom joint

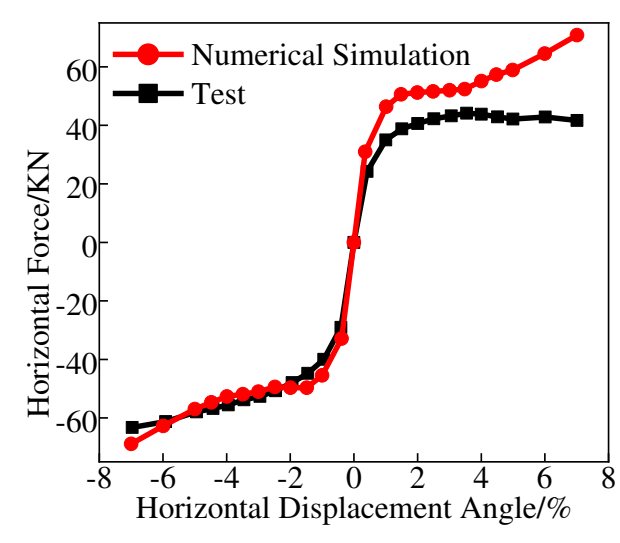

(b) Skeleton curve

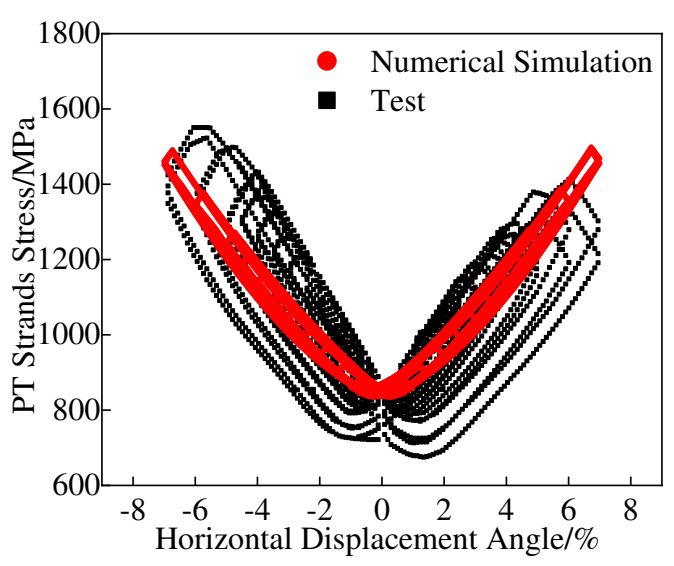

(d) Stress variation of PT strands

Fig.4 Comparison between the FE model and experimental results

To verify the accuracy of the established model, comparisons of the load-displacement hysteretic curve, skeleton curve, vertical displacement of the column bottom joint and stress variation of the PT strands from the simulated and experimental results are shown in Fig.4. The results from the FE model are in good agreement with the experimental results in the reverse loading process. Some trivial discrepancies exist in the forward loading process due to the influence of inevitable construction and loading errors, which cause an asymmetrical shape in the load-displacement curve. Comparing Fig. 3 (a) and (b), the maximum bearing capacity from the FE model and test in the reverse process is $68 \mathrm{kN}$ and $63 \mathrm{kN}$, respectively, with an error of approximately $8 \%$. Fig.3(c) shows that the maximum opening displacements of the column bottom are $15 \mathrm{~mm}$ and $13 \mathrm{~mm}$, and the maximum displacements when the joint is closed are both $55 \mathrm{mmmm}$. Fig. 3(d) shows that the maximum stress values of the prestressed reinforcement under the positive and negative horizontal displacement angles of the finite element model and the test model are 1495MPa, $1484 \mathrm{MPa}, 1412 \mathrm{MPa}$ and $1550 \mathrm{MPa}$, respectively. These comparison values indicate that the modeling method used is reasonable and that the models established in this paper can be used in the following seismic analysis with reliable calculation. 


\section{Time-varying seismic fragility analysis results}

Seismic fragility is usually defined as a probability function that structure or component exceeds its a certain ultimate condition under given seismic intensity:

$$
P_{\mathrm{f}}\left[D \geq C \mid I_{\mathrm{M}}\right]=\Phi\left[\left(\frac{\ln \left(\mu_{D} / \mu_{C}\right)}{\sqrt{\beta_{D}^{2}+\beta_{C}^{2}}}\right)\right]
$$

where, $D$ is the seismic demand; $C$ is the bearing capacity; $I_{M}$ is the seismic intensity parameter; $\mu_{C}$ and $\mu_{D}$ are the mean values of the bearing capacity and structure seismic demand respectively, $\beta_{C}$ and $\beta_{D}$ are the logarithmic standard deviations of the bearing capacity and structure seismic demand respectively. The PGA is selected as the seismic intensity parameter, denoted as $I_{\mathrm{M}}, \sqrt{\left({\beta_{D}}^{2}+\beta_{C}{ }^{2}\right)}$ is $0.5 ; \Phi(\cdot)$ is the standard normal accumulation distribution function

A linear correlation between seismic demand $(D)$ and seismic intensity parameter $\left(I_{M}\right)$ on logarithmic scale is usually used, and then seismic demand can be expressed as a function of seismic intensity parameter:

$$
\ln \left(\mu_{D}\right)=\ln (a)+b \cdot \ln \left(I_{\mathrm{M}}\right)
$$

where $a$ and $b$ are the coefficients obtained from the structural response simulations under earthquake lading.

Therefore, the quantitative formula of conditional failure probability (exceeding probability) can be obtained as:

$$
P_{\mathrm{f}}\left[D \geq C \mid I_{\mathrm{M}}\right]=\Phi\left[\left(\frac{\ln \left(a \cdot\left(I_{\mathrm{M}}\right)^{b} / \mu_{C}\right)}{0.5}\right)\right]
$$

\subsection{Ground motion selection}

Table 2 The selected ground motion

\begin{tabular}{cccccc}
\hline Station & $\begin{array}{c}\text { Earthquake } \\
\text { events }\end{array}$ & Time & Site & PGA (g) & Magnitude \\
\hline RSN-6 & Imperial & 1940 & El Centro Array \#9 & 0.28 & 6.95 \\
RSN-126 & Gazli & 1976 & Karakyr & 0.70 & 6.8 \\
RSN-737 & Loma & 1989 & Agnews State Hospital & 0.17 & 6.93 \\
RSN1100 & Kobe & 1995 & Abeno & 0.22 & 6.9 \\
RSN1147 & Kocaeli & 1999 & Ambarli & 0.25 & 7.51 \\
RSN1183 & Chi-Chi & 1999 & CHY008 & 0.12 & 7.62 \\
RSN4855 & Chuetsu-oki & 2007 & Sanjo & 0.11 & 6.8 \\
RSN5672 & Iwate & 2008 & MYG013 & 0.32 & 6.9 \\
RSN5823 & El Mayor-Cucapah & 2010 & Chihuahua & 0.25 & 7.2 \\
RSN6912 & Darfield & 2010 & Hulverstone Drive Pumping Station & 0.14 & 7 \\
\hline
\end{tabular}

Ten earthquakes that meet the local site conditions are selected from the strong earthquake database of the PEER center, as shown in Table 2. Based on these actual ground motion records and Equation (10), 10 groups of 150 ground motions are randomly generated in the range of $0.01 \mathrm{~g}-1.0 \mathrm{~g}$. 


$$
a_{g}^{(i)}(t)=k_{i} a(t)
$$

where $a_{g}^{(i)}(t)$ is the ground motion record after the first amplitude modulation; $a(t)$ is the original actual ground motion record, and $k_{i}$ is the amplitude modulation coefficient.

\subsection{Damage index}

Seismic damage can be divided into four types: minor damage, medium damage, serious damage and complete damage. The corresponding damage indexes of the four damage stages are the displacement ductility ratio of the steel bar for the first yield time $\left(\mu_{c y l}\right)$, the displacement-ductility ratio of the section equivalent yield $\left(\mu_{c y}\right)$, the displacement ductility ratio when the protecting layer strain of the bridge column is 0.004 , and the maximum displacement ductility ratio $\left(\mu_{c 4}\right)$, and the maximum displacement ductility ratio $\left(\mu_{c \max }\right)$. The definition of the damage state of the column by the displacement ductility ratio is shown in Table 3 .

Table 3 Definition of the failure state

\begin{tabular}{cc}
\hline Failure state & Failure criterion \\
\hline Nondamage & $\mu_{d} \leq \mu_{c y l}$ \\
Slight damage & $\mu_{c y l} \leq \mu_{d} \leq \mu_{c y}$ \\
Medium damage & $\mu_{c y} \leq \mu_{d} \leq \mu_{c 4}$ \\
Serious damage & $\mu_{c 4} \leq \mu_{d} \leq \mu_{\mathrm{c} 4}$ \\
Complete damage & $\mu_{c \max } \leq \mu_{d}$ \\
\hline
\end{tabular}

The expression of pier displacement ductility ratio is as follows:

$$
\mu_{\mathrm{d}}=\frac{\mathrm{D}}{\mathrm{D}_{\mathrm{cy} 1}}
$$

where, $\mu_{d}$ denotes the displacement-ductility ratio, $\Delta$ is the relative displacement of the column top under seismic conditions (mm), $\Delta_{\text {cyl }}$ is the relative displacement of the column top when the steel bar of the column bottom section yields for the first time $(\mathrm{mm})$. 


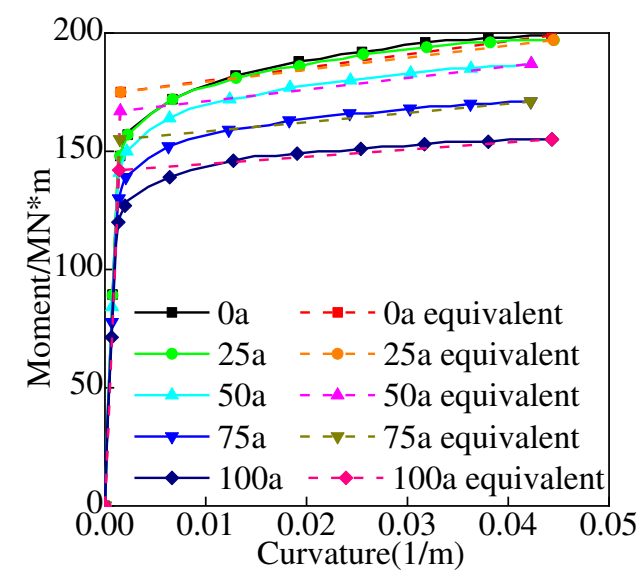

(a) $\mathrm{CPBC}$

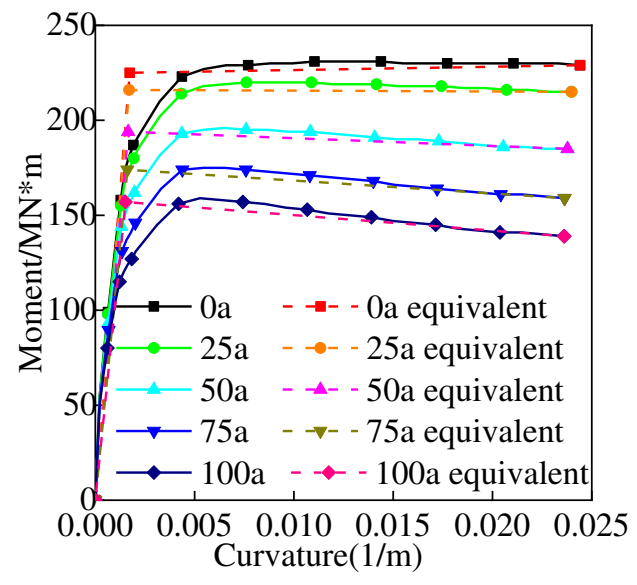

(b) PSBC

Fig.6 Time-varying moment curvature analysis

To obtain the damage index, the section moment-curvature is analyzed. Under offshore environments, the RC bridge columns in the service period are heavily affected by chloride ion erosion, and the mechanical properties of the materials will degrade, which can influence the moment-curvature change of the column section. The column moment- curvature under different service periods is shown in Fig. 6. In the whole life cycle, the mechanical properties of the reinforced steel are decreased due to the corrosion of the steel bar. The slope degradation rate of PSBC is greater than that of CPBC, and the ultimate curvature of PSBC decreases more obviously with the extension of bridge service time due to the effects of chloride ion erosion. The equivalent and ultimate bending moments of CPBC and PSBC decreased by $19 \%$, and $22 \%$ and $30 \%$, and $39 \%$, respectively, when the column reached the service life.

After the moment curvature analysis, the displacement ductility ratio can be calculated as follows:

$$
\begin{aligned}
& \mu_{\mathrm{cyl}}=1 \\
& \mu_{\mathrm{cy}}=\frac{\Delta_{\mathrm{cy}}}{\Delta_{\mathrm{cy} 1}}=\frac{\phi_{\mathrm{y}}}{\phi_{\mathrm{y}}^{\prime}} \\
& \mu_{\mathrm{c} 4}=\frac{\Delta_{\mathrm{c} 4}}{\Delta_{\mathrm{cyl} 1}} \\
& \Delta_{\mathrm{c} 4}=\Delta_{\mathrm{cy}}+\Delta_{\mathrm{p} 4}=\frac{1}{3} \cdot \phi_{\mathrm{y}} \cdot L^{2}+\theta_{\mathrm{p} 4} \cdot\left(L-\frac{1}{2} \cdot L_{\mathrm{p}}\right) \\
& \mu_{\mathrm{cmax}}=\mu_{\mathrm{c} 4}+3
\end{aligned}
$$

where, $\Delta_{c y}$ is the relative displacement of the column top when the column section yields equivalently(mm); $\Delta_{c 4} 、 \Delta_{p 4} 、 \theta_{p 4}$ is the relative displacement of the column top when the strain of concrete for column protection is $0.004(\mathrm{~mm})$, ideal elasticplastic displacement $(\mathrm{mm})$, permissible angle, respectively; $L$ is the height of the cantilever; $L_{p}$ is the length of the equivalent plastic hinge region(mm). 
Table 4 Time-varying damage indexes of CPBC and PSBC

\begin{tabular}{|c|c|c|c|c|c|c|c|c|c|c|c|c|c|c|}
\hline \multirow{3}{*}{ Time/a } & \multicolumn{2}{|c|}{$\Delta_{\text {cyl }} / \mathrm{mm}$} & \multicolumn{2}{|c|}{$\Delta_{\mathrm{cy}} / \mathrm{mm}$} & \multicolumn{2}{|c|}{$\Delta_{\mathrm{c} 4} / \mathrm{mm}$} & \multicolumn{2}{|c|}{$\mu_{\mathrm{cy} 1}$} & \multicolumn{2}{|c|}{$\mu_{\mathrm{cy}}$} & \multicolumn{2}{|c|}{$\mu_{\mathrm{c} 4}$} & \multicolumn{2}{|c|}{$\mu_{\mathrm{cmax}}$} \\
\hline & $\mathrm{CP}$ & PS & $\mathrm{CP}$ & PS & $\mathrm{CP}$ & PS & $\mathrm{CP}$ & PS & $\mathrm{CP}$ & PS & $\mathrm{CP}$ & PS & $\mathrm{CP}$ & PS \\
\hline & $\mathrm{BC}$ & $\mathrm{BC}$ & $\mathrm{BC}$ & $\mathrm{BC}$ & $\mathrm{BC}$ & $\mathrm{BC}$ & $\mathrm{BC}$ & $\mathrm{BC}$ & $\mathrm{BC}$ & $\mathrm{BC}$ & $\mathrm{BC}$ & $\mathrm{BC}$ & $\mathrm{BC}$ & $\mathrm{BC}$ \\
\hline 0 & 195.6 & 166.3 & 244.5 & 269.1 & 533.4 & 409.0 & 1 & 1 & 1.25 & 1.62 & 2.73 & 2.46 & 5.73 & 5.46 \\
\hline 25 & 195.0 & 167.3 & 243.5 & 265.3 & 530.1 & 407.3 & 1 & 1 & 1.25 & 1.59 & 2.72 & 2.43 & 5.72 & 5.43 \\
\hline 50 & 187.7 & 170.8 & 238.3 & 257.5 & 532.9 & 402.3 & 1 & 1 & 1.27 & 1.51 & 2.84 & 2.36 & 5.84 & 5.36 \\
\hline 75 & 179.5 & 174.3 & 229.7 & 250.9 & 537.4 & 396.1 & 1 & 1 & 1.28 & 1.44 & 2.99 & 2.27 & 5.99 & 5.27 \\
\hline 100 & 171.5 & 158.3 & 219.4 & 236.2 & 537.8 & 389.0 & 1 & 1 & 1.28 & 1.49 & 3.14 & 2.46 & 6.14 & 5.46 \\
\hline
\end{tabular}

Considering the service environment of the investigated columns and the related parameters in Table 1, the displacement ductility ratio can be obtained. The time-varying damage indexes of CPBC and PSBC are shown in Table 4 . In the whole life cycle, the displacement of the column top of CPBC and PSBC decrease with the extension of the service time under four damage damages; under the slight damage stage, the damage index remains unchanged, under the moderate damage, severe damage and complete damage stages, the damage index of $\mathrm{CPBC}$ increased with the extension of service time, and the damage index of PSBC decreased with the extension of service time.

\subsection{Time-variant fragility analysis}

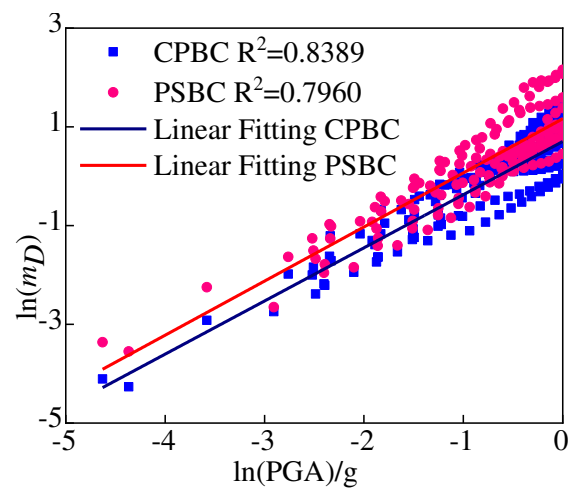

(a) $0 \mathrm{a}$

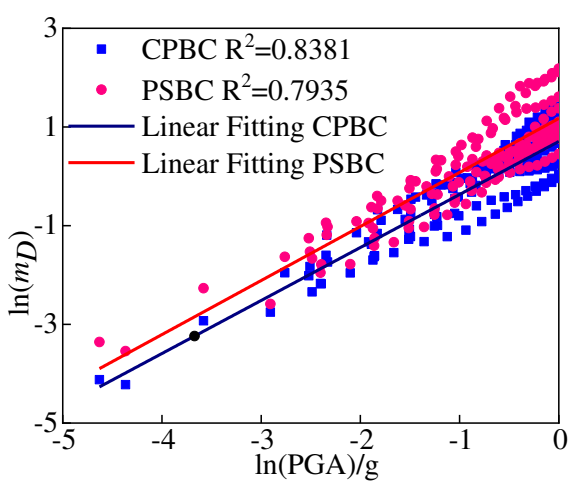

(b) $25 \mathrm{a}$

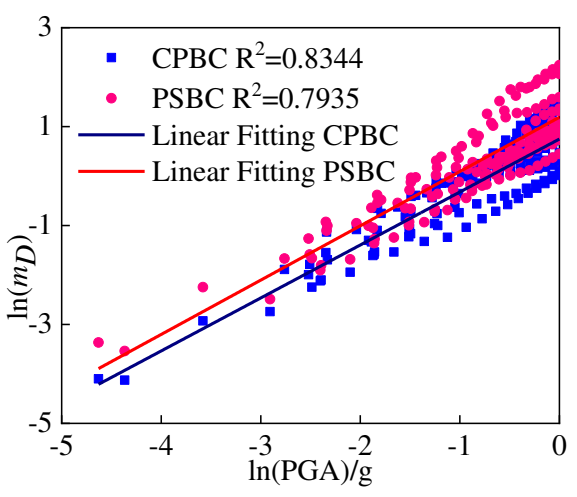

(c) $50 \mathrm{a}$
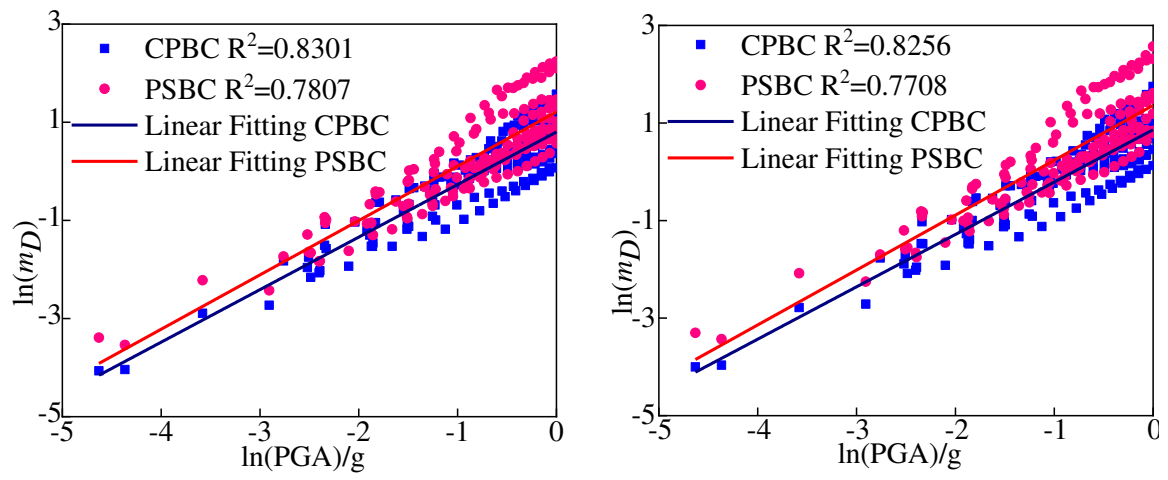
(d) $75 \mathrm{a}$

(e) $100 \mathrm{a}$

Fig.8 Probabilistic seismic demand model in different periods of service

Based on the 150 seismic waves obtained by amplitude modulation, 150 relative displacement ductility ratios corresponding to every column are selected for logarithmic linear regression analysis, the probabilistic seismic demand model between seismic demand $(D)$ and seismic intensity parameter $\left(I_{M}\right)$ is obtained, as shown in Fig. 8 . Then the exceeding probability under different damage states in the whole life cycle of the column can be calculated, the time-varying vulnerability curve can be drawn.

In the whole life cycle, the time-variant fragility surfaces of CPBC and PSBC are shown in Fig. 9 and Fig. 10. The comparison indicates that under the four damage stages, the exceeding probability of PSBC is higher than that of CPBC. Under the same stages, the growth rate of the exceeding probability of PSBC with the extension of service time is greater than that of $\mathrm{CPBC}$. Therefore, PSBC is more prone to damage than $\mathrm{CPBC}$ in the long-term service process.

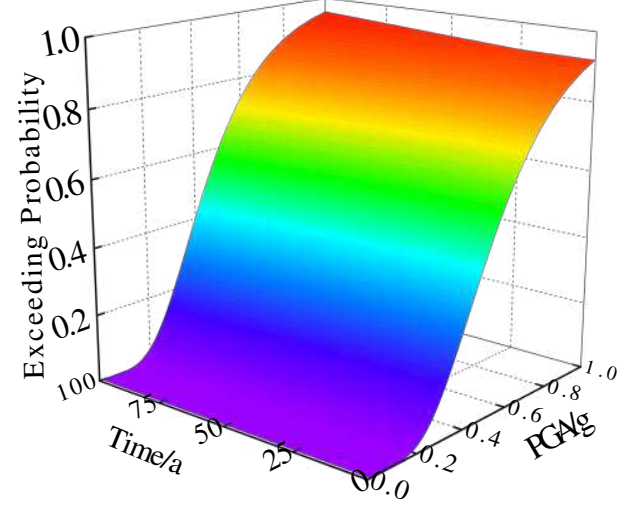

(a) Slight damage

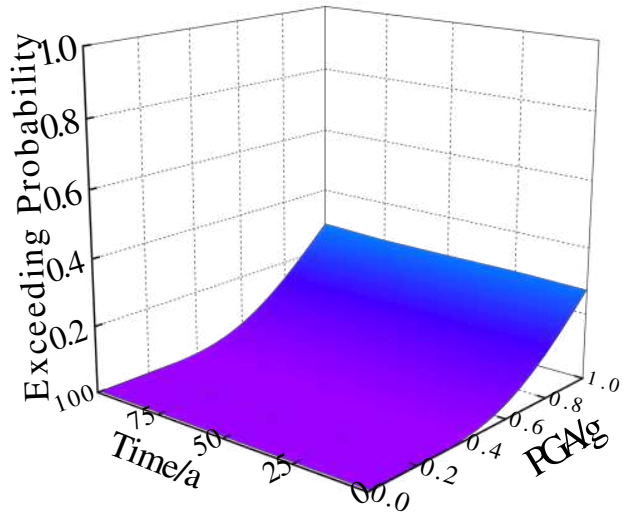

(c) Serious damage

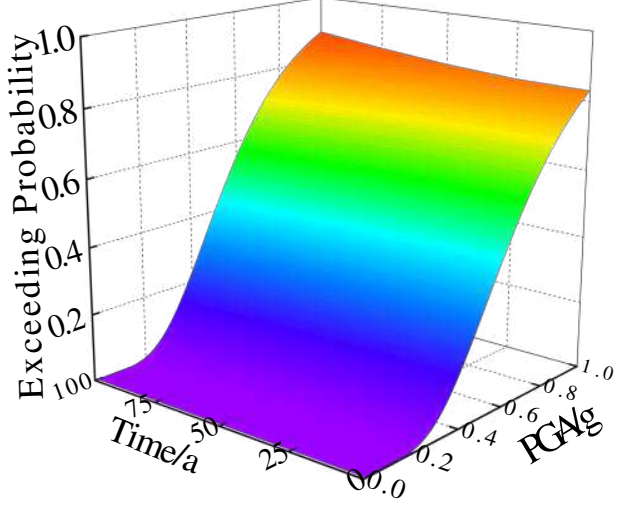

(b) Moderate damage

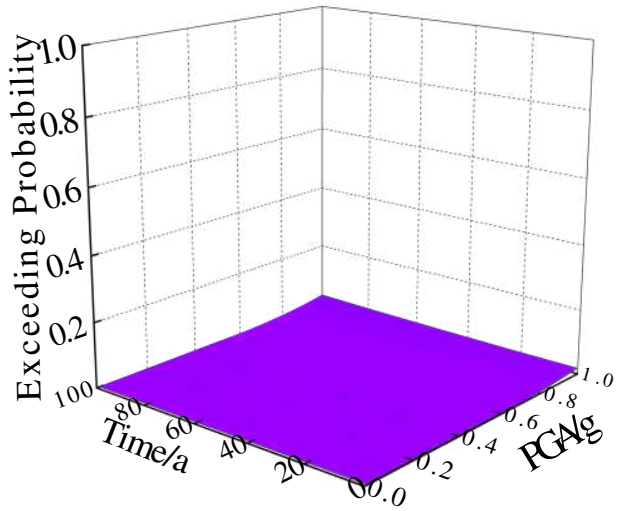

(d) Complete damage

Fig.9 CPBC time-varying fragility surface 


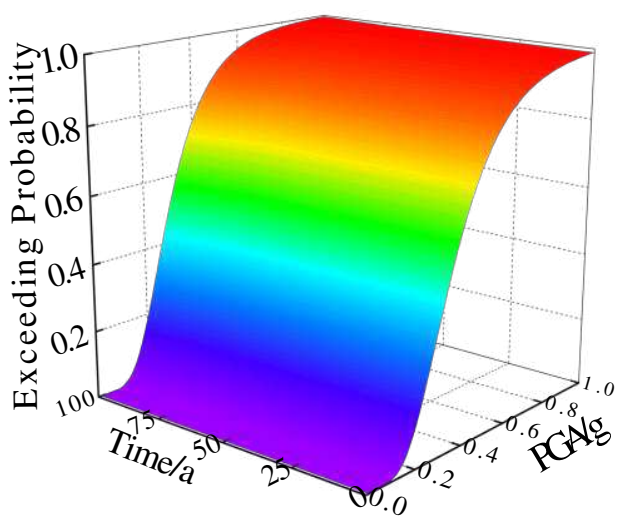

(a) Slight damage

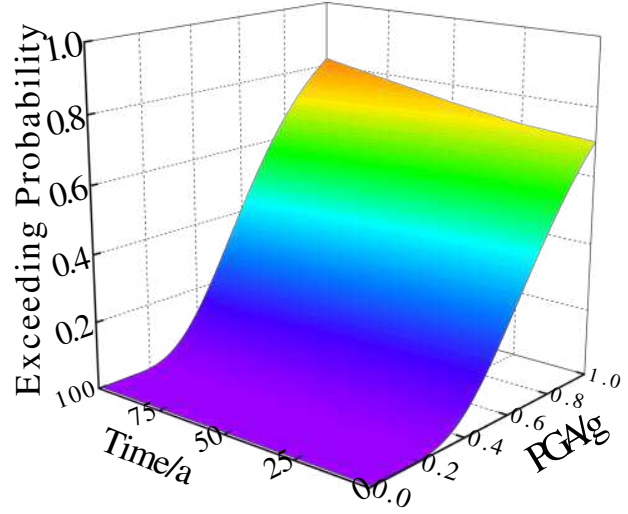

(c) Serious damage

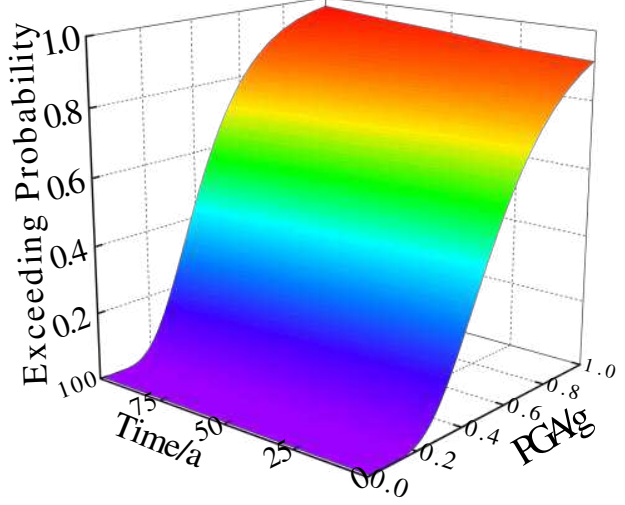

(b) Moderate damage

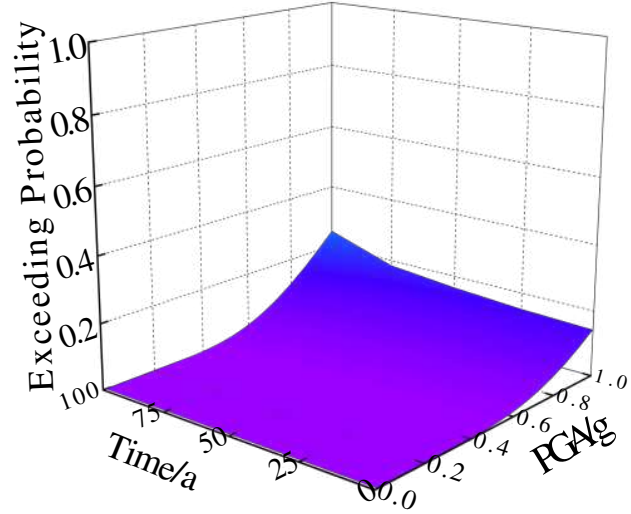

(d) Complete damage

Fig.10 PSBC time-varying fragility surface

In order to directly compare the exceeding probability of PSBC and CPBC under different PGAs in the whole life cycle, the time-varying fragility curve and the exceeding probability difference under the four damage states are drawn, as shown in Fig.11 and Fig.12.

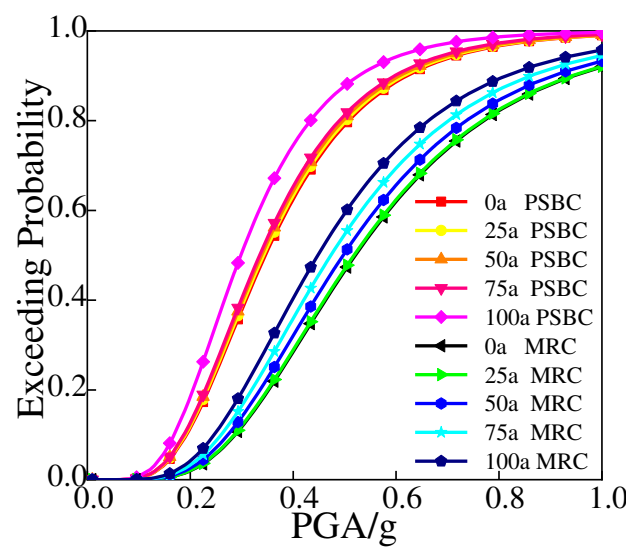

(a) Slight damage

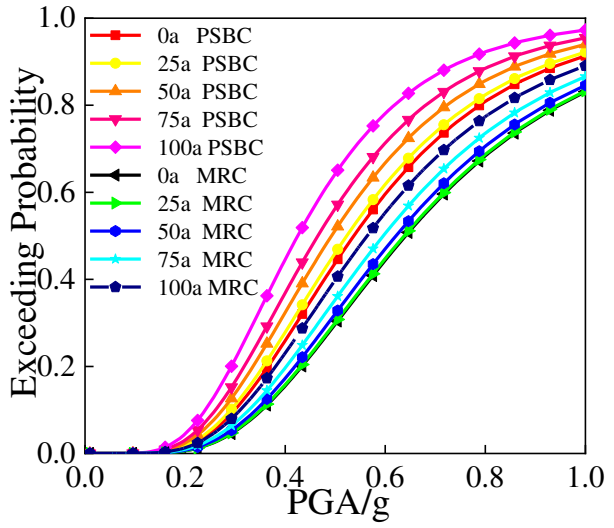

(b) Moderate damage 


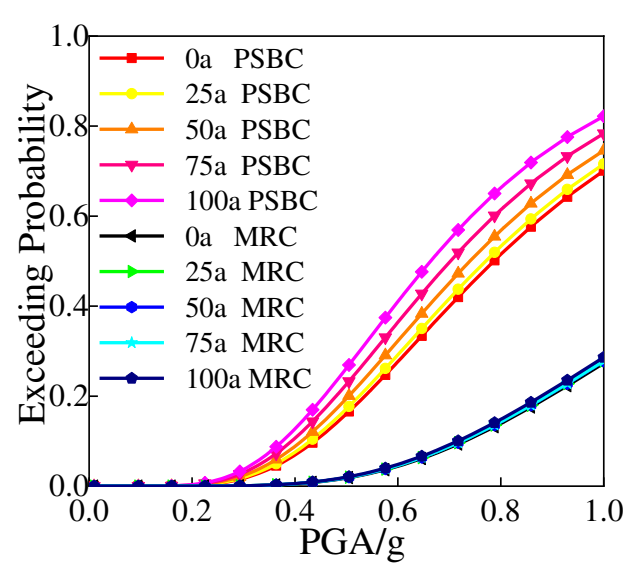

(c) Serious damage

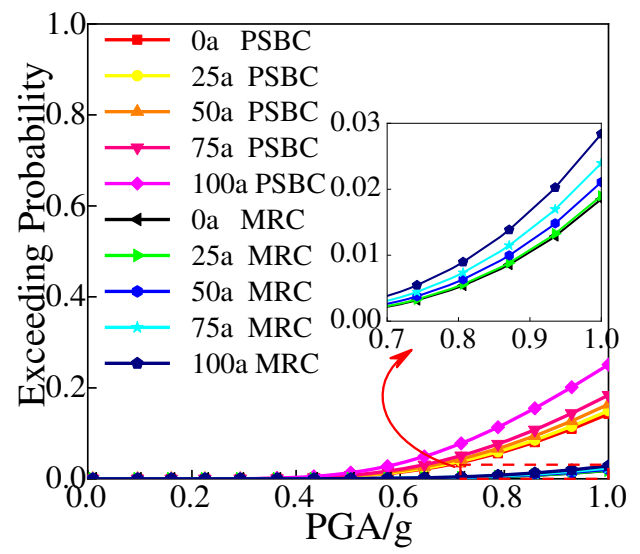

(d) Complete damage

Fig.11 Fragility curve

The exceeding probability curve under the four damage states are shown in Fig. 11. It can be seen that the exceeding probability of PSBC is always greater than that of CPBC in the whole life cycle. When the designed service life is reached, the maximum exceeding probabilities of PSBC and CPBC are $99.6 \%$ and $95.7 \%$ under the slight damage stage, which were $0.7 \%$ and $4.1 \%$ higher than that of the completed bridge, respectively. The maximum probabilities were $97.2 \%$ and $89.1 \%$ in the moderate damage stage, which were $6.5 \%$ and $7.2 \%$ higher than those in bridge completion, respectively. The maximum probability was $82.2 \%$ and $28.4 \%$, which were $17.3 \%$ and $4.8 \%$ higher than that of the bridge completed. When the bridge was completely destroyed, the maximum exceeding probability was $25.1 \%$ and $2.8 \%$, which increased by $75.6 \%$ and $53.6 \%$, compared to the bridge completed, respectively. In the four damage states, the exceeding probability of $\mathrm{CPBC}$ and PSBC increases with the extension of bridge service time and the increase of PGA. The initial corrosion time of the first row of CPBC longitudinal bars is 22 years, and that of the second row longitudinal bars is 50 years. The damage of the CPBC bridge column is small in 0-25 years. Due to the discontinuity between segments, the corrosion time in PSBC is earlier than that in CPBC, the first row of ED bars at the PSBC segment began to rust in the 8th year, and the second row began to rust in the 14th year. The exceeding probability of PSBC increased rapidly with the extension of the service time of the bridge. Taking the medium damage with $\mathrm{PGA}=0.5 \mathrm{~g}$ as an example, compared with that of the bridge when it has been in service for 25, 50, 75 and 100 years, the exceeding probability of the CPBC bridge column increased by $1.25 \%$, $8 \%, 18 \%$ and $33 \%$, and the exceeding probability of PSBC increased by $5 \%, 17 \%, 28 \%$ and $46 \%$. 


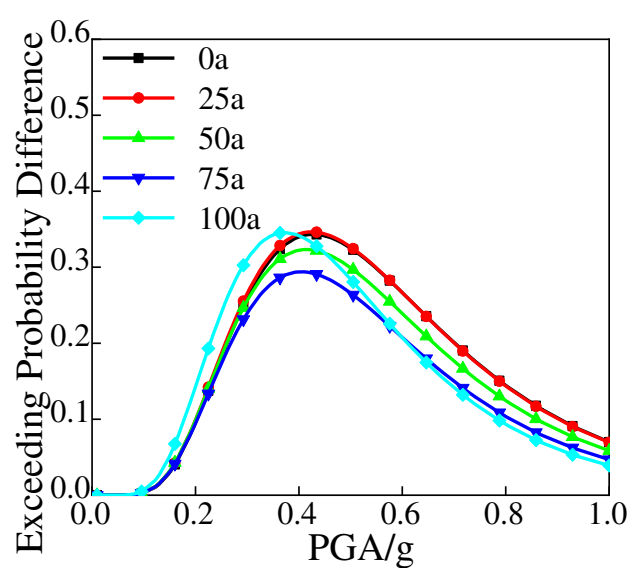

(a) Slight damage

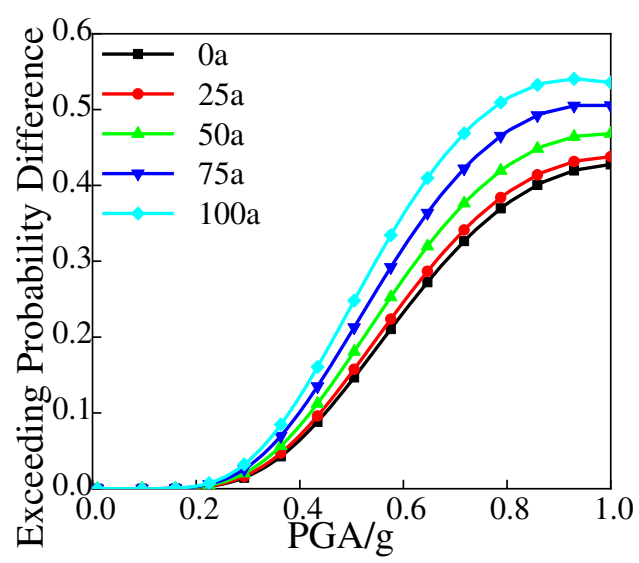

(c) Serious damage

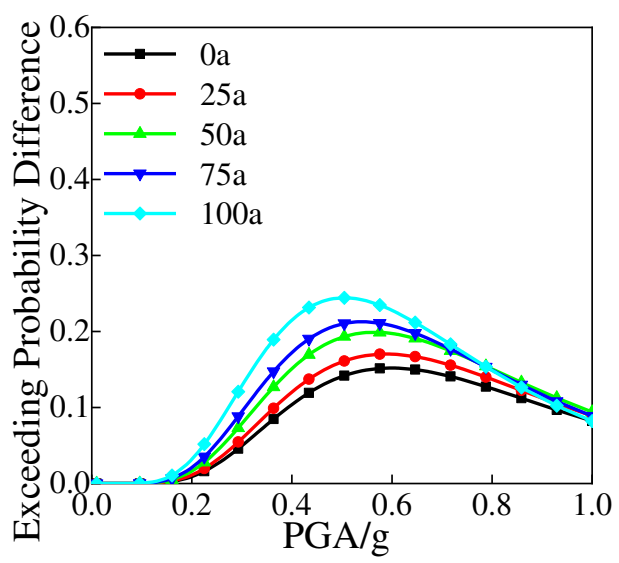

(b) Moderate damage

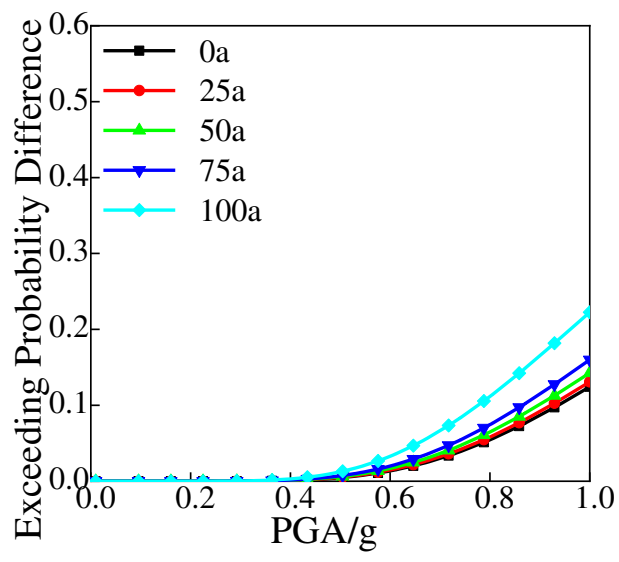

(d) Complete damage

Fig.12 Exceeding probability difference of vulnerability curve

Fig. 12 shows the difference of exceeding probability between CPBC and PSBC under four damage states. In the four damage conditions, when PGA is less than $0.3 \mathrm{~g}$, the difference of exceeding probability is small. With the increase in PGA, the exceeding probability difference reached the maximum value around $\mathrm{PGA}=0.6 \mathrm{~g}$, and the maximum exceeding probability difference was approximately $32 \%$. When PGA=1.0g, the exceeding probability difference gradually decreased to approximately $10 \%$. In the condition of severe damage and complete damage, the exceeding probability difference increases all the time and reaches the maximum value around PGA=1.0g. In the condition of severe damage, the exceeding probability difference reaches $54 \%$, and in the condition of complete damage, the exceeding probability difference reaches $22 \%$.

Supposing that the vulnerability curve follows a logarithmic positive distribution, linear regression analysis was carried out for different exceeding probabilities of PGA to calculate the median PGA, which is defined as the PGA value corresponding to exceeding $50 \%$ exceeding probability of specified damage state. The time-varying damage index of the column in different damage states is taken as the mean value of the structural seismic capacity $\mu_{C}$ replacing the mean value 
of the structural seismic demand in equation (8) $\mu_{D}$, the time-varying median PGA of the columns under different damage states can be obtained:

$$
I_{\mathrm{M}}=\mathrm{e}^{\frac{\ln \left(\mu_{C}\right)-\ln a}{b}}
$$

Table 5 Time-varying median PGA

\begin{tabular}{ccccccccc}
\hline \multirow{2}{*}{ Time/a } & \multicolumn{2}{c}{ Slight Damage } & \multicolumn{2}{c}{ Moderate Damage } & \multicolumn{2}{c}{ Serious Damage } & \multicolumn{2}{c}{ Complete Damage } \\
\cline { 2 - 9 } & CPBC & PSBC & CPBC & PSBC & CPBC & PSBC & CPBC & PSBC \\
\hline 0 & 0.521 & 0.346 & 0.64 & 0.537 & 1.322 & 0.786 & 2.633 & 1.627 \\
25 & 0.518 & 0.342 & 0.637 & 0.522 & 1.316 & 0.772 & 2.626 & 1.607 \\
50 & 0.497 & 0.338 & 0.621 & 0.492 & 1.289 & 0.739 & 2.582 & 1.561 \\
75 & 0.473 & 0.335 & 0.596 & 0.465 & 1.248 & 0.702 & 2.521 & 1.502 \\
100 & 0.448 & 0.298 & 0.563 & 0.426 & 1.190 & 0.663 & 2.427 & 1.347 \\
\hline
\end{tabular}

Then, the median time-varying PGA of CPBC and PSBC under different damage states is shown in Table 5. In the whole life cycle, under the four damage states, the median PGA of CPBC and PSBC decreased with the bridge service time extension and increased with the aggravation of damage state; The median PGA of PSBC is less than CPBC, and the reduction ratio is greater than $\mathrm{CPBC}$ with the extension of bridge service time; The corrosion time of the first row of longitudinal bars of CPBC is approximately 22 years, while the corrosion time of the second row of longitudinal bars is approximately 50 years, the median PGA at 25 years of service is not different from that at the completion of the bridge. Taking the medium damage state as an example, the median PGA at 50, 75 and 100 years of CPBC is reduced by approximately $3 \%, 7 \%$ and $12 \%$, respectively compared with that at the completion of the bridge; the corrosion time of the first row of ED bars of PSBC is approximately 8 years, while the corrosion time of the second row of ED bars is approximately 14 years, which is far earlier than that of the reinforcement in CPBC, the durability damage of PSBC is more serious than that of CPBC, the median PGA of PSBC after 0, 25, 50, 75 and 100 years of service is approximately $16 \%, 18 \%, 21 \%, 22 \%$ and $24 \%$ lower than the corresponding value of $\mathrm{CPBC}$, respectively.

\section{Conclusions}

Based on a comprehensive comparative study of the time-varying seismic fragility analysis of the PSBC and CPBC over the whole life cycle, the main conclusions are as follows:

(1) In the whole life cycle, considering the influence of chloride ion erosion, the diameter, yield strength and ultimate strength of the reinforcement decrease with the extension of the service time. After 100 years of service, the diameter, yield strength and ultimate strength of the $\mathrm{CPBC}$ reinforcement are reduced by $11 \%, 10 \%$ and $14 \%$, respectively; the diameter, 
yield strength and ultimate strength of the PSBC are reduced by $32 \%, 26 \%$ and $35 \%$, respectively.

(2) When the bridge is formed, the exceedance probability of PSBC is similar to that of CPBC in the four states, and the difference in fragility is small. With the aggravation of the damage state, the exceeding probability decreases gradually. When the damage state was relatively light, there was a small difference between PSBC and CPBC exceeding probability. When the damage state was severe, the exceeding probability of PSBC was greater than that of MR due to the discontinuity between PSBC segments. The exceeding probability of PSBC and CPBC was $99.6 \%$ and $95.7 \%$, respectively, the maximum value was $97.2 \%$ and $89.1 \%$ in moderate damage, the maximum was $82.2 \%$ and $28.4 \%$ under severe damage stage, the maximum was $25.1 \%$ and $2.8 \%$ under complete damage.

(3) In the whole life cycle, the PGA median value of CPBC and PSBC decreases with the extension of bridge service time and increases with the aggravation of the damage state. The PGA median value of PSBC is less than that of CPBC, and the durability damage of PSBC is more serious than that of CPBC. Taking the medium damage condition as an example, the median PGA of PSBC is $6 \%, 18 \%, 21 \%, 22 \%$ and $24 \%$ lower than the corresponding median PGA of CPBC when the column has been in service for $0,25,50,75$ and 100 years.

The comprehensive seismic performance of PSBC is weaker than that of CPBC, which is not conducive to popularization and application in medium- and high -intensity areas. In the follow-up, the influence of adding highperformance materials such as high-strength steel strands and UHPC on the time-varying seismic vulnerability of PSBC should be considered. At the same time, it is also necessary to further study the impact of bridge maintenance on the seismic performance and time-varying seismic vulnerability of PSBC.

\section{References}

Ahmadi, E., \& Kashani, M. M. (2021). Seismic vulnerability assessment of precast post-tensioned segmental bridge piers subject to far-fault ground motions. Structures, 34, 2566-2579. doi:10.1016/j.istruc.2021.09.041

Biondini, F., Camnasio, E., \& Palermo, A. (2014). Lifetime seismic performance of concrete bridges exposed to corrosion. Struct Infrastruct E, 10(7), 880-900. doi:10.1080/15732479.2012.761248

Bu, Z., Ou, Y., Song, J., Zhang, N., \& Lee, A. G. C. (2015). Cyclic Loading Test of Unbonded and Bonded Posttensioned Precast Segmental Bridge Columns with Circular Section. American Society of Civil Engineers. doi:10.1061/(ASCE)BE.1943-5592.0000807

Cheng, H., Li, H., Yang, Y. B., \& Wang, D. (2019). Seismic fragility analysis of deteriorating RC bridge columns with time-variant capacity index. B Earthq Eng, 17(7), 4247-4267. doi:10.1007/s10518-019-00628-x

Chou, C., \& Chen, Y. (2006). Cyclic tests of post-tensioned precast CFT segmental bridge columns with unbonded strands. 
Earthq Eng Struct D, 35(2), 159-175. doi:10.1002/eqe.512

Do, T. V., Pham, T. M., \& Hao, H. (2019). Impact Response and Capacity of Precast Concrete Segmental versus Monolithic Bridge Columns. American Society of Civil Engineers. doi:10.1061/(ASCE)BE.1943-5592.0001415

Du, Y. G., Clark, L. A., \& Chan., A. H. C. (2005). Residual capacity of corroded reinforcing bars. Mag Concrete Res, 135147. doi:10.1680/macr.2005.57.3.135

Hung, H., Sung, Y., Lin, K., Jiang, C., \& Chang, K. (2017). Experimental study and numerical simulation of precast segmental bridge columns with semi-rigid connections. Eng Struct, 136, 12-25. doi:10.1016/j.engstruct.2017.01.012

Jia, J., Zhang, K., Wu, S., Guo, Y., Du, X., \& Wang, X. (2020). Seismic performance of self-centering precast segmental bridge columns under different lateral loading directions. Eng Struct, 221, 111037. doi:10.1016/j.engstruct.2020.111037

Kashani, M. M., Ahmadi, E., Gonzalez-Buelga, A., Zhang, D., \& Scarpa, F. (2019). Layered composite entangled wire materials blocks as pre-tensioned vertebral rocking columns. Compos Struct, 214, 153-163. doi:10.1016/j.compstruct.2019.02.021

Kent, D. C., \& Park, R. (1990). Flexural Members with Confined Concrete. Journal of Structural Division Asce, 7(97), 1969-1990. doi:10.1061/JSDEAG.0003404

Lee, W. K., \& Billington, S. L. (2011). Performance-based earthquake engineering assessment of a self-centering, posttensioned concrete bridge system. Earthq Eng Struct D, 40(8), 887-902. doi:10.1002/eqe.1065

Li, C., Bi, K., \& Hao, H. (2019). Seismic performances of precast segmental column under bidirectional earthquake motions: Shake table test and numerical evaluation. Eng Struct, 187, 314-328. doi:10.1016/j.engstruct.2019.03.001

Li, C., Hao, H., Zhang, X., \& Bi, K. (2017). Experimental study of precast segmental columns with unbonded tendons under cyclic loading. Adv Struct Eng, 21(3), 319-334. doi:10.1177/1369433217717119

Li, H., Cheng, H., \& Wang, D. (2018). Time-Variant Seismic Performance of Offshore RC Bridge Columns with Uncertainty. Int J Struct Stab Dy, 18(12), 1850149. doi:10.1142/S0219455418501493

Li, T., Lin, J., \& Liu, J. (2020). Analysis of time-dependent seismic fragility of the offshore bridge under the action of scour and chloride ion corrosion. Structures (Oxford), 28, 1785-1801. doi:10.1016/j.istruc.2020.09.045

Liang, Y., Yan, J. L., Cheng, Z. Q., Chen, P., \& Ren, A. C. (2020). Time-Varying Seismic Fragility Analysis of Offshore Bridges with Continuous Rigid-Frame Girder under Main Aftershock Sequences. American Society of Civil Engineers. doi:10.1061/(ASCE)BE.1943-5592.0001578

Liang, Y., Yan, J. L., Qian, W. X., Cheng, Z. Q., \& Chen, H. (2021). Analysis of collapse resistance of offshore rigid frame - Continuous girder bridge based on time-varying fragility. Mar Struct, 75, 102844. doi:10.1016/j.marstruc.2020.102844 
Liang, Y., Yan, J., Wang, J., Zhang, P., \& He, B. (2019). Analysis on the Time-Varying Fragility of Offshore Concrete Bridge. Complexity, 2019, 1-22. doi:10.1155/2019/2739212

Ou, Y., Chiewanichakorn, M., Aref, A. J., \& Lee, G. C. (2007). Seismic Performance of Segmental Precast Unbonded Posttensioned Concrete Bridge Columns. Journal of structural engineering (New York, N.Y.), 133(11), 1636-1647. doi:10.1061/(ASCE)0733-9445(2007)133:11(1636)

Ou, Y., Tsai, M., Chang, K., \& Lee, G. C. (2010). Cyclic behavior of precast segmental concrete bridge columns with high performance or conventional steel reinforcing bars as energy dissipation bars. Earthq Eng Struct D, 39(11), 1181-1198. doi:10.1002/eqe. 986

Ou, Y., Wang, P., Tsai, M., Chang, K., \& Lee, G. C. (2010). Large-Scale Experimental Study of Precast Segmental Unbonded Posttensioned Concrete Bridge Columns for Seismic Regions. Journal of structural engineering (New York, N.Y.), 136(3), 255-264. doi:10.1061/(ASCE)ST.1943-541X.0000110

Ou, Y., \& Nguyen, N. D. (2016). Influences of location of reinforcement corrosion on seismic performance of corroded reinforced concrete beams. Eng Struct, 126, 210-223. doi:10.1016/j.engstruct.2016.07.048

Pan, W., Tao, M., \& Nie, J. (2017). Fiber beam - column element model considering reinforcement anchorage slip in the footing. B Earthq Eng, 15(3), 991-1018. doi:10.1007/s10518-016-9987-3

Rao, A. S., Lepech, M. D., \& Kiremidjian., A. (2016). Development of time-dependent fragility functions for deteriorating reinforced concrete bridge piers. Struct Infrastruct E, 67-83. doi:10.1080/15732479.2016.1198401

Sideris, P., Aref, A. J., \& Filiatrault., A. (2014). Large-Scale Seismic Testing of a Hybrid Sliding-Rocking Posttensioned Segmental Bridge System. American Society of Civil Engineers. doi:10.1061/(ASCE)ST.1943-541X.0000961

Spacone, E., \& Filippou, F. C. (1991). A Fiber Beam-Column Element for Seismic Response Analysis of Reinforced Concrete Structures. Berkekey, California:Earthquake Engineering Research Center, College of Engineering, University of California

Stewart, M. G., \& Rosowsky, D. V. (1998). Time-dependent reliability of deteriorating reinforced concrete bridge decks. Struct Saf, 20(1), 91-109. doi:https://doi.org/10.1016/S0167-4730(97)00021-0

Tong, T., Yuan, S., Zhuo, W., \& Liu, Z. (2021). Experimental and numerical investigations on cyclic behaviors of precast segmental bridge piers with the hybrid of high-strength bars and unbonded prestressing tendons. Adv Struct Eng, 24(3), 509-521. doi:10.1177/1369433220956814

Yuan, W., Guo, A., \& Li, H. (2017). Seismic failure mode of coastal bridge piers considering the effects of corrosioninduced damage. Soil Dyn Earthq Eng, 93, 135-146. doi:10.1016/j.soildyn.2016.12.002

Zhang Y, F. W. Z. Y. (2019). Experimental and Numerical Investigations on Seismic Behavior of Prefabricated Bridge 
Columns with UHPFRC Bottom Segments.

Zhanghua, X., Shangshun, L., Yongbo, H., Jiping, G., \& Jinlei, S. (2021). Seismic performance of precast bridge columns connected with grouted corrugated-metal duct through biaxial quasi-static experiment and modeling. Earthq Eng Eng Vib, 20(3), 747-770. doi:10.1007/s11803-021-2050-7.

\section{Statements \& Declarations}

\section{Fundings:}

This work was supported by [National Natural Science Foundation of China, Henan Province key research and development and promotion special project] (Grant numbers [51608488] and [212102310268]).

\section{Competing Interests:}

The authors have no relevant financial or non-financial interests to disclose.

\section{Author Contributions}

All authors contributed to the study conception and design. Material preparation, data collection and analysis were performed by [Yan Liang], [Jing-Xiao Shu] and [Yang Cao]. The first draft of the manuscript was written by [Qing-He $L i],[$ Pan-Jie Li] and all authors commented on previous versions of the manuscript. All authors read and approved the final manuscript.

\section{Data Availability}

The datasets generated during and/or analysed during the current study are available from the corresponding author on reasonable request. 